\title{
ESTUDO DAS VARIÁVEIS FÍSICO-QUÍMICAS DA ÁGUA DO MAR E DAS TINAS DE ISCA VIVA EM BARCOS ATUNEIROS
}

\author{
CAMPOS, A.F.'; SCHWINGEL, P.R. ${ }^{2}$ \& K.C. PEREIRA ${ }^{3}$ \\ 1 Doutorando PPG-ERN / Depto. Hidrobiologia / UFSCar - camposaf@terra.com.br \\ ${ }^{2}$ CTTMar/ UNIVALI - schwingel@cttmar.univali.br \\ 3 pereirak@terra.com.br
}

\begin{abstract}
RESUMO
Esse trabalho tem como objetivo determinar diferenças nas variáveis físico-químicas (oxigênio dissolvido, salinidade, $\mathrm{pH}$, nitrito, amônia, temperatura) entre a água das tinas e do mar durante a captura e manutenção das iscas vivas em barcos da frota atuneira. $O$ trabalho foi realizado durante o cruzeiro do barco "Kowalski V", na enseada de Bombinhas e entorno da ilha do Macuco, SC, entre 13 a 21 de janeiro de 2000. Os peixes utilizados como isca viva foram sardinha-verdadeira (Sardinella brasiliensis) e boqueirão (Anchoa spp). O resultado das análises de água das tinas mostrou a presença de amônia, que associada a valores altos de pH pode ocasionar queda de imunidade e causar a mortalidade de peixes devido sua toxidez. Em geral, o oxigênio dissolvido nas tinas apresentou uma diferença negativa de $2 \mathrm{mg} / \mathrm{l}$ em relação a água do mar. Temperatura, salinidade e $\mathrm{pH}$ não mostraram diferenças significativas.
\end{abstract}

Palavras-chave: isca viva, Brasil.

\section{STUDY OF PHYSICAL-CHEMICAL VARIABLE IN THE SEE WATER AND THE TANK WATER OF LIVE BAIT IN TUNA FISHING VESSEL}

\begin{abstract}
The main purpose of the present work is to determine physico-chemical differences (dissolved oxygen, $\mathrm{pH}$, salinity, nitrite, ammonia, temperature) between sea water and the tank water used for keeping live bait in a tuna fishing vessel. The study was conducted onboard the tuna vessel "Kowalski V", around the Macuco island and Bombinhas coast (Santa Catarina, Brazil) in January 2000. The main live bait were clupeid fishes (Sardinella brasiliensis and Anchoa spp.). The results revealed the presence of ammonia in tank water, which, associated with high values of $\mathrm{pH}$, can reduce the fish immunity and increase mortality. In general, the dissolved oxygen in the tank indicated a negative anomaly of $2 \mathrm{mg} / \mathrm{l}$. Temperature, salinity and $\mathrm{pH}$ showed nonsignificant differences.
\end{abstract}

Key Words: live bait, Brazil.

\section{INTRODUÇÃO}

A pesca de tunídeos (bonitos e atuns) pela frota catarinense é de grande importância para a economia da região de Itajaí e Navegantes (SC). O bonito listrado (Katsuwonus pelamis), espécie-alvo da frota, é uma espécie cosmopolita que constitui um importante recur- so pesqueiro pelágico da costa sudeste-sul do Brasil (Campos \& Andrade, 1998). No estado de Santa Catarina o desembarque desta espécie tem atingido uma média de 16 mil toneladas anuais (CEPSUL/IBAMA, 1994, 1999).

A pesca de tunídeos é feita com vara e isca viva, sendo composta por duas etapas distintas, primeiro a captura de isca viva, juvenis 
de espécies pelágicas de pequeno porte como a sardinha-verdadeira (Sardinella brasiliensis) e o boqueirão (Anchoa spp.), e em segundo lugar a pesca do bonito. Assim, existe uma relação positiva entre o sucesso da captura da isca viva e a captura do bonito. Ao contrário das outras atividades pesqueiras, essa modalidade viu-se ameaçada, não pela limitação do estoque da espécie alvo, mas sim pelo método de captura, que utiliza jovens de outras espécies como isca viva (Schwingel et al., 1999).

A captura da isca viva apresenta algumas dificuldades, como a criação de reservas ambientais onde elas ocorrem e conflitos entre pescadores industriais, artesanais e outros usuários da costa. Uma das formas de minimizar estas dificuldades, seria a realização de estudos visando uma diminuição da mortalidade nas tinas (local onde os peixes vivos são colocados) de isca viva, bem como, verificar a possibilidade de introduzir espécies alternativas nessa modalidade de pesca.

Um único estudo sobre a captura de isca viva nas regiões sul e sudeste, foi desenvolvido para estimar a quantidade de isca viva, usada na frota atuneira (Lin, 1990). Por isso, existe a necessidade de estudos mais abrangentes, integrando informações comportamentais das espécies predominantes e as características ambientais dos locais onde elas ocorrem. Lin (1998) sumarizou mapas de bordo das pescarias de bonito, relativos a frota nacional que utiliza o gelo e a salmoura na conservação do pescado, com desembarques em Santa Catarina, para os anos de 1993 e 1994, onde observou-se que o tempo para a captura da isca viva variou de 17 a $30 \%$ do total das viagens. Atualmente estimamos que esse tempo oscila entre 30 a $40 \%$.

Estudos da caracterização da água do mar nos locais de captura de isca viva e nas tinas dos barcos são ainda inexistentes. Estas informações podem auxiliar no manejo mais eficiente da isca viva, aumentando o tempo de sobrevivência dos peixes nas tinas. O objetivo deste trabalho foi verificar diferenças nas variáveis físico-químicas (oxigênio dissolvido, salinidade, $\mathrm{pH}$, nitrito, amônia, temperatura) entre a água do mar e das tinas durante a captura e manutenção das iscas.

\section{MATERIAL E MÉTODOS}

O presente estudo foi realizado durante a viagem de 9 dias à bordo do barco KOWALSKY $V$ da frota atuneira da empresa Comércio e Industria de Pescados KOWALSKY Ltda da cidade de Itajaí-SC. Esta viagem fez parte do PROFIPESCA (Programa de Formação e Qualificação Profissional na Produção Pesqueira). A atividade de captura de isca viva se deu entre 13 e 17 de janeiro de 2000. Durante este período, mediu-se nas tinas e na água do mar as seguintes variáveis: oxigênio dissolvido, salinidade, $\mathrm{pH}$, nitrito, amônia e temperatura. Para este trabalho foram utilizados "kit's" colorimétricos de campo. Todo material utilizado foi lavado com água destilada após cada análise. As tinas do barco apresentaram as seguintes capacidades: Tinas 1 e 3, 17.000 litros; e Tinas 2 e 4, 12.000 litros.

As áreas varridas na procura de isca foram localizadas no litoral de Santa Catarina, a saber: Araçá, Cachadaço, Bombinhas, Zimbros, Quatro Ilhas, Canto Grande, entorno da llha do Macuco. A coleta de amostras de água do mar e da tina para análise foi feita em Bombinhas no dia $13 / 01 / 2000$ às $22: 00$ horas, no dia 14/ 01/2000 às 06:00 horas e na Ilha do Macuco, dia 15/01/2000 às 14:00 horas. Foram estimadas também as quantidades de cada espécie de isca viva capturada (Tabela 1). Duas vezes ao dia (manhã e noite) as tinas eram limpas, retirando-se os peixes mortos, através da abertura dos "ralos" e da utilização de sifonamento.

\section{RESULTADOS}

\section{Captura da Isca viva}

O horário de captura dos peixes utilizados para isca viva se concentra em dois perío- 
dos, início da manhã e início da noite. Os resultados obtidos em relação a quantidade (peso e porcentagem) e espécies capturadas de isca viva, podem ser visualizados na Tabela 1. Os locais onde a captura não obteve sucesso são apresentados na Tabela 2.

\section{Análise da Água do Mar e das Tinas nos Lo- cais de Captura da Isca viva:}

Os dados dos gráficos foram tratados como diferenças em relação aos dados do ambiente natural (água do mar). No entorno da ilha do Macuco a água do mar apresentou a concentração de oxigênio dissolvido maior quando comparada com a das tinas (Figura 1). $\mathrm{Na}$ área de Bombinhas, o oxigênio dissolvido para as 22:00 h, foi semelhante na água do mar e na Tina 3. Por outro lado, nas medidas tomadas as 06:00 h verificou-se valores menores de oxigênio dissolvido em relação a água do mar para ambas as tinas. Em geral, o oxigênio dissolvido nas tinas apresentou uma diferença negativa de $2 \mathrm{mg} / \mathrm{l}$.

A salinidade medida no entorno da ilha do Macuco foi semelhante a da Tina 3, e apresentou uma diferença negativa de 1 PSU na Tina 1. Para a análise de água em Bombinhas no horário de 22:00 h a Tina 3 apresentou valor mais baixo em relação à água do mar (2 PSU). Os dados coletados as 06:00 h mostraram que a salinidade medida, tanto para a água do mar e para as tinas apresentaram os mesmos valores (Figura 2). Estas estimativas, mostram que existe uma leve tendência em encontrarmos salinidades menores nas tinas em relação ao ambiente natural.

Os valores de $\mathrm{pH}$ foram alcalinos em $100 \%$ das medições realizadas no presente estudo. A medição às 14:00 h no entorno da ilha do Macuco apresentou valores semelhantes para Tina 3 e água do ambiente natural. $\mathrm{Na}$ Tina 1 foi observado uma diferença negativa de 0,2 . Às 22:00 h em Bombinhas, o pH foi igual para Tina 3 e água do mar. Entretanto para às 06:00 h a Tina 3 apresentou pH igual a água do mar e na Tina 1 verificou-se uma diferença positiva de 0,2 (Figura 3). As diferenças de $\mathrm{pH}$ observadas foram relativamente baixas.

Para temperatura, os valores observados durante o período do trabalho, tanto no ambiente natural quanto nas tinas, manteve-se constante $\left(27^{\circ} \mathrm{C}\right)$. No entorno da ilha do Macuco, a análise da água da Tina 3 mostrou a presença de amônia. Para o nitrito, não foram medidos valores acima de zero.

Tabela 1: Resultado positivo na captura de isca viva, no período de 13/01/2000 até 16/01/2000, na costa catarinense. Nota: Um total de $630 \mathrm{~kg}$ de isca viva, capturadas em 114 horas, foram distribuídos nas tinas da seguinte forma: Tina $1=220 \mathrm{~kg}$; Tina $2=90 \mathrm{~kg}$; Tina $3=154 \mathrm{~kg}$; Tina $4=120 \mathrm{~kg}$.

\begin{tabular}{|c|c|c|c|c|}
\hline $\begin{array}{l}\text { Local de captura } \\
\text { (Praia/Município) }\end{array}$ & Data & $\begin{array}{c}\text { Destino da } \\
\text { isca viva (TINA) }\end{array}$ & $\begin{array}{l}\text { Quantidade de isca } \\
\text { viva }(\mathrm{Kg})\end{array}$ & Espécie e porcentagem na captura \\
\hline Araçá/Porto Belo & $13 / 01 / 00$ & 3 & 60 & $\begin{array}{c}\text { sardinha-verdadeira (Sardinella brasiliensis) } \\
90 \%, \\
\text { sardinha-casca-dura (Harengula clupeola) } \\
10 \%\end{array}$ \\
\hline $\begin{array}{l}\text { Cachadaço/ } \\
\text { Porto Belo }\end{array}$ & $13 / 01 / 00$ & 3 & 24 & $\begin{array}{c}\text { sardinha-verdadeira } 70 \%, \\
\text { boqueirão (Anchoa spp.) } 30 \%\end{array}$ \\
\hline $\begin{array}{l}\text { Bombinhas/ } \\
\text { Bombinhas }\end{array}$ & $13 / 01 / 00$ & 2 e 3 & 60 & sardinha-verdadeira $100 \%$ \\
\hline $\begin{array}{l}\text { Canto Grande/ } \\
\text { Bombinhas }\end{array}$ & $14 / 01 / 00$ & 1 e 3 & 80 & $\begin{array}{l}\text { sardinha-verdadeira } 60 \% \\
\text { sardinha casca dura } 40 \%\end{array}$ \\
\hline Macuco/ Bombinhas & $15 / 01 / 00$ & 1 e 2 & 120 & $\begin{array}{l}\text { sardinha-verdadeira } 50 \% \text {, } \\
\text { sardinha-casca-dura } 20 \% \text {, boqueirão } 30 \%\end{array}$ \\
\hline Macuco/ Bombinhas & $16 / 01 / 00$ & 1 e 4 & 240 & $\begin{array}{l}\text { sardinha-verdadeira } 60 \% \\
\text { sardinha-casca-dura } 40 \%\end{array}$ \\
\hline
\end{tabular}


Tabela 2: Resultado negativo na captura de isca viva, no período de 14/01/2000 até $16 / 01 / 2000$, na costa catarinense.

\begin{tabular}{|c|c|c|}
\hline $\begin{array}{l}\text { Local de captura } \\
\text { (Praia/Munícipio) }\end{array}$ & Data & Isca viva \\
\hline Zimbros/Porto Belo & $14 / 01 / 00$ & isca não encontrada \\
\hline Quatro Ilhas/Bombinhas & $14 / 01 / 00$ & sardinha-casca-dura $^{1}$ \\
\hline Quatro Ilhas/Bombinhas & $14 / 01 / 00$ & sardinha-casca-dura $^{1}$ \\
\hline Araçá/Porto Belo & $16 / 01 / 00$ & isca não encontrada \\
\hline
\end{tabular}

${ }^{1}$ A tripulação ao avistar um cardume de sardinha e identificando-a como casca-dura, suspende o manejo de cerco no cardume, pois esta espécie não é bem aceita, principalmente pelo bonito.

\section{DISCUSSÃO E CONCLUSÕES}

Com a presença de peixes dentro das tinas são gerados resíduos e reciclados em processos biológicos as custas do consumo de oxigênio e simultânea geração de diversos metabólitos tóxicos à isca viva, como a amônia, o nitrito e o gás carbônico. Processos biológicos como a respiração e fotossíntese injetam e removem, diariamente, grandes quantidades de oxigênio e gás carbônico na água. Devido à reação ácida do gás carbônico na água, esta pode apresentar flutuações diárias nos valores de $\mathrm{pH}$. Baseado nos valores obtidos de oxigênio dissolvido durante o estudo, apesar da diferença nos teores entre a água do mar e água das tinas ter sido relativamente alta, observou-se que provavelmente a mortalidade da isca viva que ocorreu durante a viagem, não esteja diretamente relacionada com os teores de oxigênio nas tinas (sistemas com alta renovação de água). As maiores diferenças do teor de oxigênio foram observadas no entorno da Ilha do Macuco devido ao horário de coleta de dados, pois durante o dia ocorre a fotossíntese que resulta na elevação da concentração deste gás. Em Bombinhas essas diferenças foram menores devido a ausência de fotossíntese no período noturno.

De forma geral, os valores de salinidade e temperatura nas tinas se mostraram semeIhantes aos encontrados no ambiente natural, não alterando as condições físico-químicas na água para a isca confinada.

Apesar de não encontrarmos diferenças significantes nos valores de $\mathrm{pH}$, esse parâmetro deveria ser constantemente monitorado, pois ele regula a toxidez de metabólitos como a amônia e gás sulfídrico. Valores altos de $\mathrm{pH}$ aumentam a concentração de amônia não ionizada (forma tóxica para os peixes) onde acima de $0,20 \mathrm{mg} / \mathrm{l}$ já são suficientes para induzir uma toxicidade crônica levando a diminuição da tolerância dos peixes às doenças. Observou-se que alguns peixes, principalmente os que ficam em contato direto com a malha da rede dos "saricos", sofrem lesões e descamações, abrindo assim, caminho para a entrada de patógenos, o que muitas vezes pode levar os peixes a morte na transferência e/ou ao longo da viagem. Quanto ao manejo da isca viva, deve ser o mais cuidadoso possível, para que as perdas com mortalidade sejam menores. Nos últimos anos a maior dificuldade na pesca de tunídeos com vara e isca viva é a captura e manutenção dos juvenis das espéci-
Entorno da llha do Macuco

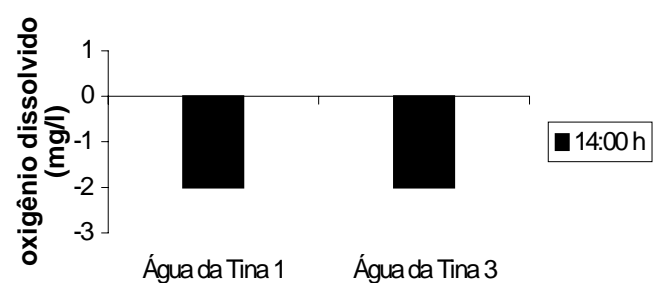

Bombinhas

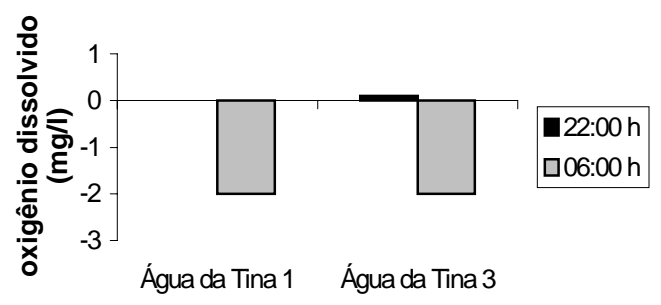

Figura. 1. Diferenças nas medidas de oxigênio dissolvido registradas no entorno da llha do Macuco e em Bombinhas. 
Entorno da llha do Macuco

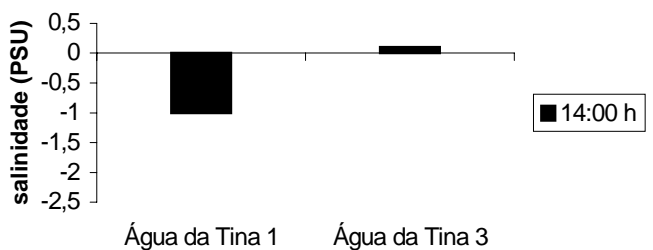

Bombinhas

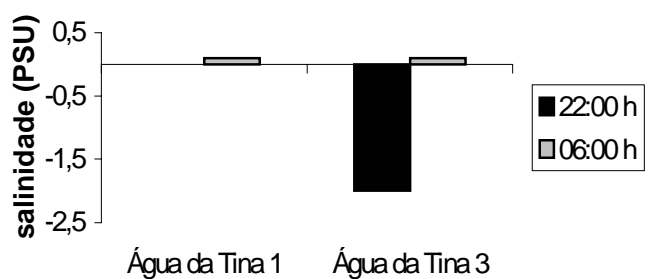

Figura. 2. Diferenças nas medidas de salinidade registradas no entorno da llha do Macuco e em Bombinhas.

es pelágicas, através da utilização de equipamentos corretos e operações de cercos e transferências cuidadosas da isca viva. Com a prática do monitoramento de algumas variáveis físico-químicas e biológicas nas tinas, podese diminuir a mortalidade, associada com manejos preventivos ou até curativos.

O acompanhamento da isca viva a bordo deve utilizar também as observações práticas dos pescadores, pois estes já conhecem as condições disponíveis para as iscas nas embarcações. Um maior conhecimento da capacidade de filtração-alimentação dos peixes dentro das tinas; da qualidade da água nas tinas, de um adequado transporte de isca viva no barco durante a captura dos cardumes de bonito, podem reduzir a mortalidade da isca confinada.

\section{AGRADECIMENTOS}

Agradecemos a Ind. e Com. de Pescados Kowalsky Ltda, e a tripulação do barco
Entorno da llha do Macuco

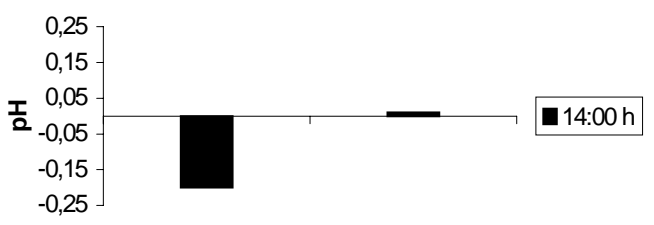

Água da Tina 1 Água da Tina 3

Bombinhas

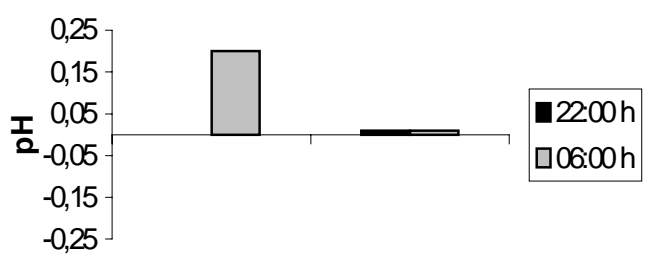

ÁguadaTina1 ÁguadaTina3

Figura 3. Diferenças nas medidas de $\mathrm{pH}$ registradas no entorno da ilha do Macuco e em Bombinhas.

Kowalski V, em especial ao mestre Aurino Custódio, pelo apoio na execução deste trabaIho.

\section{BIBLIOGRAFIA}

Campos, R. O. \& H. A. Andrade. 1998. Uma metodologia para estimativa de captura por área de pesca a partir de dados pouco informativos: o caso da pescaria de bonito listrado (Katsuwonus pelamis) na costa do Brasil. Notas Téc. FACIMAR, 2: 61-69.

CEPSUL/IBAMA. 1994. Atuns e afins e da sardinha. Coleção Meio Ambiente. Série Estudos - Pesca, n 11, Brasília. 201pp.

CEPSUL/IBAMA. 1999. Informe da pesca extrativa marinha em Santa Catarina 1997. Itajaí. 37pp.

Lin, C. F. 1990. Estimativa da quantidade de isca viva utilizada pela frota atuneira no ano de 1989, no Estado de Santa Catarina. CEPSUL/IBAMA, Brasília. 44pp. 
Lin, C. F. 1998. Pescaria de tunídeos com vara e isca viva - Santa Catarina - 1993/94. CEPSUL/IBAMA. Brasília. 108pp.

Schwingel, P.R.; Wahrlich, R.; Bailon, M.A. \& M. Rodrigues-Ribeiro. 1999. Diagnóstico da pesca do bonito listrado (Katsuwonus pelamis) com vara e isca viva no Estado de Santa Catarina. CTTMar/UNIVALI, Itajaí. 18pp. 